\title{
Mental Health and Quality of Life of Disable Palestinian Children in the Gaza Strip
}

\author{
Abdel Aziz Thabet ${ }^{*}$, Ahmed Abu Tawahina ${ }^{2}$, David Henley3 , Henrick Pelling4, \\ Panos Vostanis ${ }^{5}$, Kamal Abu Qamar6 \\ ${ }^{1}$ School of Public Health, Al Quds University, Gaza, Palestine \\ ${ }^{2}$ Gaza Community Mental Health Programme, Gaza, Palestine \\ ${ }^{3}$ University Children's Hospital, Uppsala University, Uppsala, Sweden \\ ${ }^{4}$ Department of Child Psychiatry, University Hospital, Uppsala, Sweden \\ ${ }^{5}$ University of Leicester, Greenwood Institute of Child Health, Leicester, UK \\ ${ }^{6}$ National Society for Rehabilitation, Gaza, Palestine \\ Email: abdelaziz.thabet@gmail.com, ahmedtawahina@gmail.com, david.henley@bredband.net, \\ henrik.pelling@akademiska.se, pv11@leicester.ac.u, ncbrgaza@palnet.com
}

Received 31 March 2015; accepted 11 August 2015; published 14 August 2015

Copyright (C) 2015 by authors and Scientific Research Publishing Inc.

This work is licensed under the Creative Commons Attribution International License (CC BY).

http://creativecommons.org/licenses/by/4.0/

(c) (i) Open Access

\section{Abstract}

The aim of the study was to investigate the prevalence of mental health problems and quality of life among Palestinian disable children. The sample consisted of 391 disable Palestinian children in the Gaza Strip which was selected randomly from the data base of two NGOs working with such group of children. The age of children ranged from 6 - 18 years with mean age (11.73). Instruments: The children and adolescents demographic data were collected by questionnaire include sex, age, class, and place of residence, Gaza Child Health Study Scales (parents and children forms), and The Pediatric Quality of Life Inventory generic core (version 4.0) scale. The results showed that children reported mean conduct disorder was 1.33; oppositional disorder was 5; mean overanxious was 6.75; separation anxiety mean was 6.36; and depression was 7.57. There were statistically significant differences toward boys in depression. According to parents, mean conduct disorder mean was 1.94; mean oppositional disorder was 6.09; mean overanxious was 7.47; separation anxiety mean was 6.48; and mean depression was 9.6. The study showed that mean depression in boys was 10.4 compared to 8.9 in girls. There were statistically significant differences toward boys in depression. Parents of children with physical disabilities reported more overanxious problems in their children compared to other parents with other types of disabilities (vision, mental, and multiple). Also, parents of children with physical disability had more separation anxiety than other groups (mental and multiple disabilities). Quality of life of children was scored by children themselves; mean emotional functioning was 8.24; mean social functioning was 6.65; school functioning mean was 9.17; and cognitive functioning was 8.57 . The study showed that

\footnotetext{
*Corresponding author.
}

How to cite this paper: Thabet, A.A., Tawahina, A.A., Henley, D., Pelling, H., Vostanis, P. and Qamar, K.A. (2015) Mental Health and Quality of Life of Disable Palestinian Children in the Gaza Strip. Health, 7, 994-1006.

http://dx.doi.org/10.4236/health.2015.78117 
mental health problems rated by children such as conduct disorder was positively correlated with emotional and cognitive functioning; oppositional disorder was correlated with emotional, social, and cognitive function; overanxious disorder was correlated emotional, school, and cognitive functioning; separation anxiety was correlated emotional functioning; and depression was correlated emotional, social, and cognitive functioning.

\title{
Keywords
}

\author{
Disabled Children, Mental Health Problems, Quality of Life, Gaza Strip
}

\section{Introduction}

Disability and incidence of disability in Arab countries are challenging subjects for some factors; few indexed publications, limited statistics; reliability is questionable, sociability in definitions and different methodologies.

According to the WHO, disability is "an umbrella term, covering impairments, activity limitations, and participation restriction. Thus, disability is a complex phenomenon, reflecting an interaction between features of a person's body and features of the society in which he or she lives" [1].

In a meeting in Cairo in 2002, UN-ESCWA recommended some measurements to have reliable date, including training interviews to improve the quality of data collection, sensitivity training, and better phrasing of questions [2]. For example, Jordan's official 2001 estimated disability in $12.6 \%$ of population [3], 10 times higher than the 1994 figure of $1.2 \%$ [2].

Persons living with some form of disability account for about $15 \%$ of the world population [4]. The records of National Society for Rehabilitation and Palestinian Medical Relief Society in Gaza Strip showed that 35,866 persons were identified with one disability at least according to WHO criteria, which represented $2.5 \%$ of total population of the Gaza Strip. According to place of residence, $13.8 \%$ live in North Gaza; 28.2\% live in Gaza; 23.4\% live in Middle zone; $24.6 \%$ live in Khan Younis area; and 10\% live in Rafah. Of this number, 57.3\% were males and $42.7 \%$ were females. For age, $36.4 \%$ were under 18 years old and $63.6 \%$ above 18 years old. The data showed that the most common type of disability was vision $33.24 \%$, followed by physical disability $31.78 \%$, speech impairment $4.69 \%$, learning impairment $5.48 \%$, mental problems $2.36 \%$, hearing disability 7.78\%, multiple disabilities $14.23 \%$, and other disabilities $0.44 \%$ [5].

From the mid-1990s onwards Goodman and colleagues conducted and reported a series of studies undertaken in children with hemiplegia identified from the London area.

In an intensive study of 428 children with hemiplegia aged 2.5 - 16 years using standardized measures, with a subset of these children undergoing individual psychiatric assessment. The rate of psychiatric problems was high with more than half the children (61\%) having psychiatric problems, based on individual assessment or as judged by their parents (54\%). The types of disorders experienced by the children studied intensively included emotional disorder (25\%), which tended to be anxieties and fears; conduct disorder (24\%), which most often presented as irritability and oppositional behaviours in contrast to antisocial behaviours; situational hyperactivity (13\%) and pervasive hyperactivity (10\%); with autistic and other disorders occurring rarely (3\% respectively) [6]. Even among the most able children with hemiplegia (mild motor impairment, IQ more than 90, at mainstream school without a history of seizures) the rate of psychiatric problems was 39\%. Follow-up data (four years later) were available for $90 \%$ of the children included in the above study. In another longitudinal study of stability of psychiatric problems in a sample of children with hemiplegia and found that the majority of children with hemiplegia assessed at time one still had psychiatric problems by time two (70\%). In addition, a further 30\% of children without problems at time one developed difficulties by time two [7].

A study examined in detail the social experiences of 55 children with hemiplegia at mainstream school. These children were part of the larger cohort, and all had an IQ greater than 60. The study involved matching the children with hemiplegia to 55 classmate controls and undertaking a number of interviews and sociometric measures to explore peer relations of children with hemiplegia. Overall children with hemiplegia were twice as likely as their peers to be rejected; they were twice as likely to have no or few friends; they were three times more likely to be victimized and; according to teacher reports, they were less likely than their classmate control 
to initiate aggressive or bullying behaviours with other children—which suggested they were not initiating all the difficulties [8].

Despite something of a mixed picture presented by single studies, meta-analyses and systematic reviews [9] had concluded that the balance of evidence would indicate that children with chronic illnesses and disabilities were indeed at increased risk for emotional and behavioural disturbance and that this risk was exacerbated if neurological deficits were implicated. Also, a study of 818 children with cerebral palsy, aged 8 - 12 years, identified from population-based registers of cerebral palsy in eight European regions and from multiple sources in one further region. Main outcome measures: The Strengths and Difficulties Questionnaire (SDQ) and the Total Difficulties Score (TDS), about a quarter of the children had TDS $>16$ indicating significant psychological symptoms, most commonly in the domain peer problems. Better gross motor function, poorer intellect, more pain, having a disabled or ill sibling and living in a town were independently associated with TDS $>16$. Among parents who reported their child having psychological problems, 95\% said they had lasted over a year; 37\% said they distressed their child and $42 \%$ said they burdened the family at least "quite a lot" [10]. Furthermore, in a cross-sectional study, children with CP between 6 and 12 years of age in Canada showed 27.6\% of the sample scoring in the clinically abnormal range and an additional $11.8 \%$ reporting borderline total scores. Peer problems were the most common (55.3\%), followed by emotional symptoms (40.8\%), hyperactivity (30.3\%), lack of prosocial behaviours (27.6\%) and conduct problems (22.4\%). Moreover, a study of 160 adolescents with cerebral palsy in Canada using SDQ, showed that difficulties score was $36.9 \%$ of the sample and included $18.8 \%$ of the adolescents who scored in the clinically abnormal range, and $18.1 \%$ in the borderline range. When combining borderline and abnormal scores, the most frequent difficulties were: peer problems (61.9\%), emotional symptoms (4.4\%), conduct problems (21.3\%), hyperactivity (20.0\%), and lack of prosocial behaviors (15.6\%) [11].

Many quality of life (QOL) definitions have been put forward in the international literature. Good quality of life (QoL) is a key outcome for the individual child and is what society wants for all children [12]. Quality of life is defined by WHO as "an individual's perception of their position in life in the context of the culture and value systems in which they live, and in relation to their goals, expectations, standards and concerns" [13]. However, QoL seems to contain similar major ideas: (a) a life of quality is based on individual needs, choices, and control and is experienced when his or her needs are met and when he or she has the opportunity to pursue life enrichment in major life environments across the life span [14]; and (b) QOL, including both subjective and objective aspects, is a multidimensional construct consisting of personal and environmental factors [15]. Quality of life (QoL) is therefore, subjective and so must be reported by the individual concerned whenever possible. This is a challenge when assessing children's QoL because they have typically been regarded as unreliable respondents [16]. Evidence is accumulating that children can be self-report QoL reliably if their emotional development, cognitive ability, and reading level are taken into account [17]. Interest in the measurement of healthrelated quality of life (HRQoL) has increased considerably over the past years, with a growing appreciation of the importance of the patient's perspective [18]. According to the World Health Organization, HRQoL is to be regarded as a multi-dimensional concept that includes physical, social, cognitive and emotional functioning [19]. The subjective perception and appraisal of functioning are as important as objective health, because individuals with the same objective health status may report very different quality of life [20]. For assessing HRQoL in pediatric populations, there is wide agreement that instruments should be multidimensional, sensitive to cognitive development, easy to complete, and encompass the broadest age range possible. Furthermore, they should meet the psychometric requirements of sensitivity, reliability and validity [16] [21]-[23]. According to reports in the literature, children with cerebral palsy report lower quality of life scores than healthy children across most dimensions, and these scores do not appear to improve over time [24]. Others reported different results: psychosocial domains were less severely affected than physical domains. According to parental reports, children with CP have reduced quality of life (as measured by a quality of life inventory), and the degree of impact is related to the severity of the condition [25]. In the vastness of difference that can occur in the symptomology of children with CP, it is important to remember that true physical disability may or may not be different than the disability perceived by the child. The significance of this relates to identifying methods and types of potential interventions if true disability and perceived disability have similar psychosocial implications [26]. Moreover, larger studies with sufficient power to control for relevant factors have shown that quality of life is very similar in children with cerebral palsy and non-disabled children [27] [28]. 
The aim of the study was to investigate the prevalence of mental-health problems among disable Palestinian children and their quality of life in relation to types of disability and other sociodemographic factors.

\section{Method}

\subsection{Participants}

The sample chosen was a stratified random sample based on the records of the database of both the National Society for Rehabilitation (NSR) and Palestinian Medical Relief Society (PMRS), whereas the Gaza Strip was divided into five governorates (the North, Gaza, Mid Zone, Khan Younis, and Rafah), selected children and adolescents were from the active cases (cases are currently involved in the services) and inactive cases (cases received services in the past) in the period 2005-2009. The sample size was determined by the intention to reach a 95\% confidence level. The study sample was 400 Palestinian. Only 391 children data were collected, nine children who did not complete the questionnaires during the interviews in their homes with response rate of $97.7 \%$. They aged ranged from $6-18$ years old (Mean $=11.73(\mathrm{SD}=3.52)$, and there were no gender differences according to age $(F(1,384)=0.42, p=n s$. $)$.

\subsection{Study Procedure}

Before starting the data collection, the principal investigator conducted training for one day for data collectors (25 male and females) inside their organization (National Society for Rehabilitation-NSR). On this day, we explained the aim of the study and discussed with them the different obstacles that they could face and how to interview the children with the already prepared questionnaire. The field work was conducted by community based rehabilitation workers who give support for such target group. They visited the families according to prepared lists of number of names of children selected from the Database of the NSR (National Society for Rehabilitation) \& PMRS (Palestinian Medical Relief Society). The field workers presented an information letter to the parents and asked for their consent to allow participation of their children in the study. Children were interviewed individually at their homes and each an interview lasted approximately 60 minutes. The interviewers informed children that there was no right or wrong answers, provided guidance infilling-up the scales. Children and parents were also informed that they were free to withdraw from the study at any time.

\section{Measures}

\subsection{Sociodemographic Data}

The children and adolescents demographic data was were collected by questionnaire include sex, age, class, and place of residence.

\subsection{Revised Ontario Child Health Study Scales [29]}

Revised Ontario child health study (OCHS) scales measure conduct disorder, oppositional disorder, attention deficit hyperactivity disorder, overanxious disorder, separation anxiety and depression based on DSM-III-R symptom criteria and contains items adapted from the Child Behavior Checklist [30]. Questionnaires were developed to be completed by parents, teachers of children in school, and adolescents aged $12-16$. A value of 0,1 or 2 was assigned to represent the symptom. For internalizing (e.g., worries about things in the future; needs to be told over and over that things are okay) there are three subscales; overanxious ( 7 items), separation anxiety (9 items), depression (9 items) and externalizing (e.g., kicks, bites, or hits other children; defiant, talks back to adults) symptoms there were three subscales; conduct (12 items), oppositional defiant (9 items) and attention deficit (14 items). The Arabic version was validated by translation and back translation of the English version, and was sent to panel of experts to validate the items of the scale. The reliability test of the subscales was done for both parents and children scales. Cronbach's alpha for parents reported conduct disorder, attention deficit disorder, oppositional defiant disorder, overanxious disorder, separation anxiety, and depression was $(0.80,0.88$, 0.87, 0.85, 0.77, and 0.77). While, Cronbach's alpha for children reported conduct disorder, attention deficit disorder, oppositional defiant disorder, overanxious disorder, separation anxiety, and depression was $(0.80,0.89$, $0.85,0.72,0.85$, and 0.74$)$. 


\subsection{The Pediatric Quality of Life Inventory Generic Core (Version 4.0) Scale Arabic Versions [31]}

It is a brief, 28-item multidimensional instrument designed for measuring pediatric health-related quality of life. The Pediatric Quality of Life Inventory consists of 4 generic core scales: 1) Physical Functioning, 2) Emotional Functioning, 3) Social Functioning, and 4) School Functioning. For this study, the parent proxy-report format was used [21]. The instructions ask how much of a problem each item has posed over the past month. The response scale uses a 5-point Likert-type format, ranging from 0 (never a problem) to 4 (almost always a problem). The raw score for each item is reverse-scored and transformed to a scale from 0 to 100 (0 - 100, 1 - 75, 2 - 50, 3 - 25, and 4 - 0), with higher scores indicating better health-related quality of life To create the total scale score, the mean is computed as the sum of the items divided by the number of items answered on all scales. To determine the psychosocial health summary score, the sum of items divided by the number of items answered on the emotional, social, school and cognitive functioning scales was computed. In this study we used the Arabic version of the scale and we excluded the physical component of the scale due to the specifity of the disabled children [31]. Cronbach's alpha for emotional, social, school and cognitive functioning scales was $(0.71,0.71,0.62$, and 0.91).

\subsection{Statistical Analysis}

The data was analyzed using the statistical package for social sciences (SPSS) program (version 18.0). Descriptive techniques were used to examine the similarities and differences of variables associated with type of disabilities of children and quality of life and mental health problems. The statistical significance of differences was assessed using two-tailed independent samples t-tests $(p<0.05)$. One Way ANOVA test was performed to test the statistical significance of between more than two group differences for distributions and means. The Pearson correlation was used to examine the relationship between quality of life and mental health problems.

\section{Results}

\subsection{Sociodemographic Characteristic of the Study}

As shown in Table 1, the sample responded to the interview were 391 participants with response rate of $97.7 \%$, it consisted of 192 males (49.1\%) and 199 girls (50.9\%). The age of children ranged from 6 - 18 years with mean age of 11.53 years (SD = 3.5). According to place residence $14.3 \%$ of children were from North Gaza, 27.6\% were from Gaza, 18.8\% were from Middle area, 13.8\% were from Khan Younis, and 25.3\% were from Rafah area (south of Gaza). According to type of residence, 43.7\% of children live in cities, 43.5\% live in villages, and $12.8 \%$ live in camps. In looking for the family monthly income, $29.9 \%$ had no income, $51.9 \%$ of the families monthly income was less than $\$ 250$ per month, 15.1\% earned \$251 - 500, and only 3.1\% earned more than $\$ 501$.

\subsection{Characteristics of the Disability of the Children}

As shown in Table 2 , the study showed that $40.66 \%$ of disabled children have physical disability, $34.8 \%$ had vision disability $13.3 \%$ had multiple disability whereas, $4.6 \%$ had hearing impairment, 3.32\% had speech disability, and $3.32 \%$ had mental disability. Also, it was noticed from the results that $23.8 \%$ of disability was attributed to heredity factors, $48.6 \%$ for congenital, $9 \%$ for the last war on the Gaza Strip. The majority of children $80.6 \%$ reported that their disability is back to several years, $19.4 \%$ was before 6 months of the study. Regard rehabilitation status of cases, $56.3 \%$ of the disabled children were currently active cases (currently receiving services) with both societies, and $43.7 \%$ were inactive (currently not receiving services) and their files were closed.

\subsection{Means and Standard Deviations of Mental Health Problems Rated by Parents and Children}

As shown in Table 3, the results showed that mean conduct disorder by children mean was $2(\mathrm{SD}=2.83)$ and by parents was $1.9(\mathrm{SD}=2.94)$, attention deficit hyperactivity rated by children was $10.97(\mathrm{SD}=7.19)$ and by parents was 7.2 (SD = 5.24), oppositional defiant disorder by children was 4.67 (SD 4.2) and by parents was 6.09 $(\mathrm{SD}=4.7)$, mean overanxious disorder by children was $4.86(\mathrm{SD}=3.11)$ and by parents was $5.91(\mathrm{SD}=3.3)$, 
Table 1. Sociodemographic characteristics of the study sample $(\mathrm{N}=381)$.

\begin{tabular}{|c|c|c|}
\hline & $\mathrm{N}$ & $\%$ \\
\hline \multicolumn{3}{|l|}{ Sex } \\
\hline Boys & 192 & 49.1 \\
\hline Girls & 199 & 50.9 \\
\hline Age & Mean 11.73 (SD = 3.5 years) & \\
\hline \multicolumn{3}{|l|}{ Address } \\
\hline North Gaza & 56 & 14.3 \\
\hline Gaza & 108 & 27.6 \\
\hline Middle area & 74 & 18.9 \\
\hline Khan Younis & 54 & 13.8 \\
\hline Rafah area & 99 & 25.3 \\
\hline \multicolumn{3}{|l|}{ Place of residence } \\
\hline City & 171 & 43.7 \\
\hline Village & 170 & 43.5 \\
\hline Camp & 50 & 12.8 \\
\hline \multicolumn{3}{|c|}{ Family monthly income } \\
\hline No income & 117 & 29.9 \\
\hline Less than $\$ 250$ & 203 & 51.9 \\
\hline$\$ 251-\$ 500$ & 59 & 15.1 \\
\hline More than $\$ 501$ & 12 & 3.1 \\
\hline \multicolumn{3}{|l|}{ Job } \\
\hline Student & 168 & 48.8 \\
\hline Unemployed & 119 & 34.6 \\
\hline Employee & 30 & 8.7 \\
\hline Merchant & 3 & 0.9 \\
\hline Simple worker & 23 & 6.7 \\
\hline Others & 1 & 0.3 \\
\hline
\end{tabular}

Table 2. Characteristics of the disable children.

\begin{tabular}{rccc}
\hline Type of disability & N & \% \\
\hline Physical & 159 & 40.66 \\
Visual & 136 & 34.78 \\
Multiple & 52 & 13.30 \\
Hearing & 18 & 4.60 \\
Speech & 13 & 3.32 \\
Mental & 13 & 3.32 \\
\hline
\end{tabular}




\section{Continued}

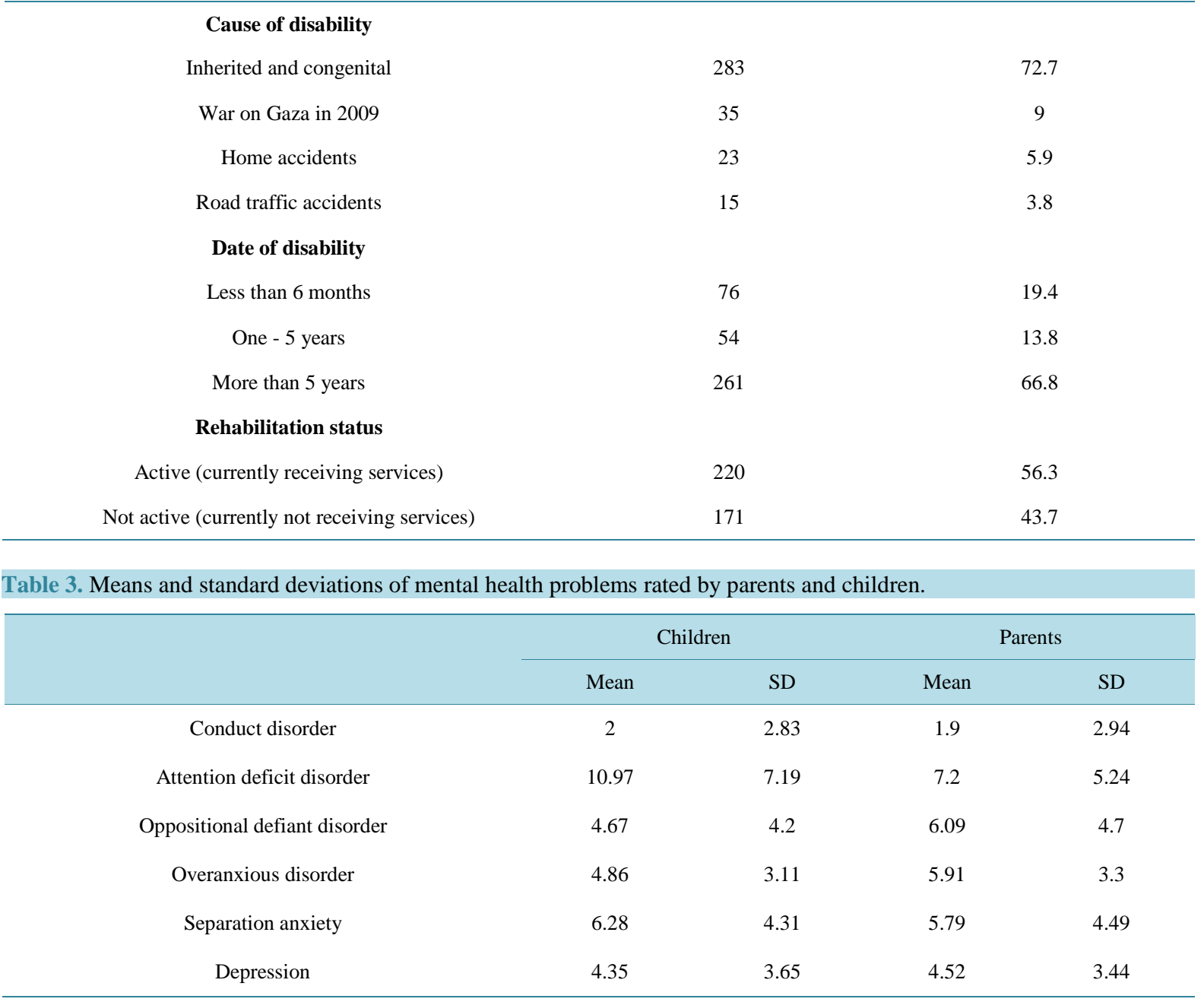

Table 3. Means and standard deviations of mental health problems rated by parents and children.

separation anxiety mean by children was $6.28(\mathrm{SD}=4.31)$, and by parents was $5.79(\mathrm{SD}=4.49)$, mean depression by children was $4.52(\mathrm{SD}=3.44)$.

\subsection{Differences in Mental Health Problems Rated by Parents and Children According to Sex and Age of Children}

The study showed that there were no statistically significant differences in mental health problems rated by parents and children and gender and age.

\subsection{Differences in Mental Health Problems According to Type of Disabilities}

In order to find the differences in mental health problems according to types of disabilities, One-Way ANOVA was conducted. Post hoc test using LSD test showed that parents of children with physical disabilities reported more overanxious problems in their children compared to other parents with other types of disabilities (vision, mental, and multiple) $(\mathrm{F}=2.44, p<0.05)$. Also, parents of children with physical disability had reported more separation anxiety in their children than other groups (parents of children with mental and multiple disabilities) $(\mathrm{F}=3.07, p<0.01)$.

Parents of children with visual disabilities reported more separation anxiety problems in their children than parents of children with mental health problems. However, no other differences in other mental health problems such as conduct, depression, oppositional, attention-deficit and type of disabilities rated by parents. 


\subsection{Differences in Mental Health Problems Rated by Children Themselves According to Sex}

In order to differences in mental health problems according to sex of children, $\mathrm{t}$ independent test was conducted in which sex was dependent variable and other mental health problems as independent variables. The results showed that mean depression in boys was $8.3(\mathrm{SD}=7.1)$ compared to $6.8(\mathrm{SD}=5.7)$ in girls. There were statistically significant differences toward boys in depression ( $\mathrm{t}$-test $=2.36, p<0.02$ ). However, no sex differences in other mental health problems.

\subsection{Differences in Mental Health Problems Rated by Children Themselves According to Age of Children}

The results showed that there was statically significant correlation between age of the handicapped children and attention deficit disorder, older aged children had more attention deficit problems than younger age group $(\mathrm{r}=$ $-0.11, p<0.04)$. No age differences in other mental health problems.

\subsection{Differences in Mental Health Problems Rated by Children Themselves According to Type of Disabilities}

In order to find the differences in mental health problems according to types of disabilities, One-Way ANOVA was conducted. Post hoc test using LSD test showed that children with physical and visual disabilities reported more overanxious problems compared to children with other types of disabilities (hearing and mental disabilities) $(\mathrm{F}=2.32, p<0.05)$. Also, children with physical and visual disabilities reported more separation anxiety in children compared to children with other types of disabilities (hearing and mental disabilities) ) $\mathrm{F}=2.49, p<$ 0.05). Children with physical disabilities reported more depression compared to children with children with visual disabilities $(\mathrm{F}=2.52, p<0.05)$.

\subsection{Differences in Mental Health Problems According to Cause of Disabilities}

In order to find the differences in mental health problems according to causes of disabilities, One-Way ANOVA was conducted. Post hoc test using LSD test showed that children with disabilities due to war on Gaza reported less separation anxiety compared to children with disability due to home accidents and genetic problems, but they had more separation anxiety than children with disabilities due to home accidents $(\mathrm{F}=3.38, p<0.05)$. Also children with disability due to home accidents were more overanxious than other group (disability due to war on Gaza).

\subsection{Quality of Life in Handicapped Children}

\subsubsection{Emotional Functioning}

The study showed that $16.88 \%$ of children said they feel afraid and scared, $16.62 \%$ were worried about what will happen, and $15.86 \%$ feel angry. $11.25 \%$ having trouble sleeping and $9.72 \%$ of children said they are feeling sad or blue.

\subsubsection{Social Functioning (SF)}

The social function of the children showed that $10.74 \%$ had difficulty keeping up with others and $9.21 \%$ had trouble getting along with peers.

\subsubsection{School Functioning (SC)}

The study showed that $37.34 \%$ said they keep up with schoolwork, and $23.02 \%$ said they pay attention at class.

\subsubsection{Cognitive Functioning (CG)}

The study showed that $13.04 \%$ said that they have difficulty remembering more than one thing at a time and $11.76 \%$ said they had difficulty thinking quickly.

\subsection{Means and Standard Deviation of QOL and Subscales}

As shown in Table 4, the study showed that mean Total Quality of life was 30.85 (SD = 14.48), mean emotional 
Table 4. Means and Standard deviation of QOL and subscales.

\begin{tabular}{cccc}
\hline QOL & No. of items & Mean & SD \\
\hline Total quality of life & 21 & 30.85 & 14.48 \\
Emotional functioning & 5 & 8.24 & 5.17 \\
Social functioning & 5 & 6.65 & 4.82 \\
School functioning & 5 & 9.17 & 4.51 \\
Cognitive functioning & 6 & 8.57 & 6.67 \\
\hline
\end{tabular}

functioning was 8.24 (SD = 5.17), mean social functioning was 6.65 ( $\mathrm{SD}=4.82)$, school functioning mean was $9.17(\mathrm{SD}=4.51)$, and cognitive functioning was $8.57(\mathrm{SD}=6.67)$.

\subsection{Differences in Quality of Life Rated by Children According to Sex}

In order to differences in quality of life according to sex of children, $t$ independent test was conducted in which sex was dependent variable and subscales of quality of life as independent variables. There were no statistically significant differences in total quality of life between boys and girls, there was statistically significant difference in cognitive functioning toward boys that girls $(\mathrm{t}=2.20, p<0.03)$.

\subsection{Differences in Quality of Life Rated by Children According to Age of Children}

The results showed that there was statistically significant differences between age of the handicapped children and quality of life, older aged children had less social functioning than younger age group $(\mathrm{r}=-0.11, p<0.02)$. No age differences in other total quality of life and other subscales.

\subsection{Relationship between Mental Health Problems in Disable Children According to Parents and Children Themselves, and Quality of Life of Children}

In order to find the relationship between quality of life and mental health problems rated by parents and children, Pearson coefficient correlation test was conducted.

As shown in Table 5, for parents report, the study showed that emotion functioning was negatively correlated with conduct $(\mathrm{r}=-0.14, p=0.001)$, oppositional defiant disorder $(\mathrm{r}=-0.20, p=0.001)$, attention deficit disorder $(\mathrm{r}=-0.18, p=0.001)$, overanxious disorder $(\mathrm{r}=-0.24, p=0.001)$, and separation anxiety $(\mathrm{r}=-0.18 p=$ $0.001)$. While, social functioning was positively correlated with conduct $(\mathrm{r}=0.11, p=0.001)$, oppositional defiant disorder $(\mathrm{r}=0.32, p=0.001)$, attention deficit disorder $(\mathrm{r}=0.23, p=0.001)$, overanxious disorder $(\mathrm{r}=0.32$, $p=0.001)$, and separation anxiety $(0.26 p=0.001)$, and depression $(\mathrm{r}=0.27, p=0.001)$. Also, school functioning was positively correlated with oppositional defiant disorder $(\mathrm{r}=0.14, p=0.001)$, attention deficit disorder $(\mathrm{r}$ $=0.17, p=0.001)$, and depression $(r=0.27, p=0.001)$. Moreover, cognitive functioning was positively correlated with conduct $(\mathrm{r}=0.11, p=0.001)$, oppositional defiant disorder $(\mathrm{r}=0.15, p=0.001)$, attention deficit disorder $(r=0.11, p=0.001)$, and overanxious disorder $(r=0.16, p=0.001)$.

For children report, emotional functioning of children was negatively correlated with conduct $(r=-0.13, p=$ $0.001)$, oppositional defiant disorder $(\mathrm{r}=-0.21, p=0.001)$, attention deficit disorder $(\mathrm{r}=-0.19, p=0.001)$, overanxious disorder $(\mathrm{r}=-0.23, p=0.001)$, and separation anxiety $(-0.19 p=0.001)$. Moreover, social functioning was positively correlated with conduct $(\mathrm{r}=0.21, p=0.001)$, oppositional defiant disorder $(\mathrm{r}=0.29, p=$ $0.001)$, attention deficit disorder $(\mathrm{r}=0.25, p=0.001)$, overanxious disorder $(\mathrm{r}=0.36, p=0.001)$, separation anxiety $(\mathrm{r}=0.27, p=0.001)$, and depression $(\mathrm{r}=0.13, p=0.001)$.

Also, social functioning was positively correlated with conduct $(\mathrm{r}=0.15, p=0.001)$, oppositional defiant disorder $(\mathrm{r}=0.20, p=0.001)$, attention deficit disorder $(\mathrm{r}=0.14, p=0.001)$, overanxious disorder $(\mathrm{r}=0.12, p$ $=0.001)$, and depression $(r=0.24, p=0.001)$.

Also, school functioning was positively correlated with conduct $(r=0.15, p=0.001)$, oppositional defiant disorder $(r=0.20, p=0.001)$, attention deficit disorder $(\mathrm{r}=0.14, p=0.001)$, overanxious disorder $(\mathrm{r}=0.12, p$ $=0.001)$, and depression $(r=0.24, p=0.001)$. Moreover, cognitive function was positively correlated with 
Table 5. Correlation Coefficients between mental health problems in disable children according to parents, self, and quality of life of children.

\begin{tabular}{|c|c|c|c|c|}
\hline & Emotional function & Social function & School function & Cognitive function \\
\hline Conduct disorder-parents report & $-0.14^{* *}$ & $0.11^{*}$ & 0.08 & 0.06 \\
\hline Oppositional defiant disorder—parents & $-0.20^{* *}$ & $0.32^{* *}$ & $0.14^{* *}$ & 0.08 \\
\hline Attention deficit disorder—parents & $-0.18^{* *}$ & $0.23^{* *}$ & $0.17^{* *}$ & 0.09 \\
\hline Overanxious-parents report & $-0.24^{* *}$ & $0.32^{* *}$ & 0.02 & $0.13^{* *}$ \\
\hline Separation anxiety—parents & $-0.18^{* *}$ & $0.26^{* *}$ & 0.06 & 0.10 \\
\hline Depression—parents reports & -0.09 & $0.27^{* *}$ & $0.27^{* *}$ & $0.10^{*}$ \\
\hline Conduct disorder—self report & $-0.13^{*}$ & $0.21^{* *}$ & $0.15^{* *}$ & $0.11^{*}$ \\
\hline Oppositional defiant disorder—self & $-0.21^{* *}$ & $0.29^{* *}$ & $0.20^{* *}$ & $0.15^{* *}$ \\
\hline Attention deficit disorder—self & $-0.19^{* *}$ & $0.25^{* *}$ & $0.14^{* *}$ & $0.11^{*}$ \\
\hline Overanxious—self & $-0.23^{* *}$ & $0.36^{* *}$ & $0.12^{*}$ & $0.16^{* *}$ \\
\hline Separation anxiety—self & $-0.19^{* *}$ & $0.27^{* *}$ & 0.08 & 0.09 \\
\hline Depression—child reports & -0.07 & $0.13^{* *}$ & $0.24^{* *}$ & 0.06 \\
\hline
\end{tabular}

conduct $(\mathrm{r}=0.11, p=0.001)$, oppositional defiant disorder $(\mathrm{r}=0.15, p=0.001)$, attention deficit disorder $(\mathrm{r}=$ $0.11, p=0.001)$, and overanxious disorder $(\mathrm{r}=0.16, p=0.001)$.

\subsection{Quality of Life and Children Mental Health Problems}

Regression analyses about the predictive mental health problems of quality of life are presented in Table 5. The models were significant for overanxious disorder reported by the child and oppositional disorder reported by the parents, explaining, however, only $10 \%$ of the variation. Significant $\beta$-values indicate that children reported overanxious disorder $(\beta=0.17, \mathrm{t}=4.14, p<0.002)$ and oppositional disorder by parents $(\beta=0.17, \mathrm{t}=3.06, p<$ 0.002 ) were associated by quality of life.

\section{Discussion}

This study showed that the main causes of disability in Palestinian children in the Gaza Strip were attributed to heredity and congenital factors; other causes of disability were war, home accidents, and road traffic accidents. This high level of heredity cause could be attributed to the first-degree-cousin consanguinity marriage in the Gaza Strip. This is consistent with study in Egypt suggested that genetic diseases may be responsible for twothirds of childhood blindness in Arab societies, ranging from 47\% in Tunisia to 86\% in Kuwait [32]. Studies had found a higher prevalence rate of disabilities in rural areas in developing countries [4].

In a study of disability and poverty in developing countries found, disability is significantly associated with higher multidimensional poverty in most of the developing countries under study. In other words, as a group, persons with disabilities, on average, experience multiple deprivations at higher rates and in higher breadth, depth, and severity than persons without disabilities [33].

The results showed that parents reported mean attention deficit hyperactivity was 9.62, conduct disorder was 1.94 , oppositional disorder was 6.09 , overanxious was 7.47 , separation anxiety was 6.48 , and depression was 9.6. While children themselves reported that mean attention deficit hyperactivity was 3.64 , conduct disorder was 1.31, oppositional disorder was 5 , overanxious was 6.75 , separation anxiety was 6.36 , and depression was 7.57 . This is consistent with study of in study of an Australian children reported that $40 \%$ of 454 children with intellectual disabilities aged 4 - 18 met criteria for psychiatric caseness, compared with 14\% of Australian children without intellectual disabilities identified in a random community sample [34]. Also, in the UK, a secondary analysis of surveys of representative samples of 18,415 children aged 5 - 15 reported that $36 \%$ of 641 children operationally defined as intellectually disabled met criteria for an ICD-10 psychiatric disorder compared with 8\% 
of 17,774 children without intellectual disabilities. In terms of specific psychiatric disorders, this study reported significantly higher rates of emotional disorder, anxiety disorder, hyperkinesis, conduct disorder, autistic-spectrum disorder and tic disorder although there were no significant differences in the prevalence of depressive disorder or eating disorder [35].

The study showed that mean emotional functioning was $8.24(\mathrm{SD}=5.17)$, mean social functioning was 6.65 ( $\mathrm{SD}=4.82)$, school functioning mean was $9.17(\mathrm{SD}=4.51)$, and cognitive functioning was $8.57(\mathrm{SD}=6.67)$. Others reported slightly different results: Psychosocial domains were less severely affected than physical domains [25]. According to parental reports, children with CP have reduced quality of life (as measured by a quality of life inventory, and the degree of impact is related to the severity of the condition. In a study of quality of life of cerebral palsy children showed significant deficits in health related quality of life (HRQOL) for children with cerebral palsy (CP). Most of the effects were related to physical functioning issues and impact on the parents or caregivers. Psychosocial HRQOL was better than physical HRQOL. The relations among increasing number of medical problems, severity of CP, and reduced HRQOL were not surprising. A significant brain insult resulting in severe symptoms [36].

\section{Conclusion}

This study highlights the suffering of children with different disabilities and showed that their quality of life is low compared to other normal children. According to reports in the literature, children with CP report lower quality of life scores than healthy children across most dimensions, and these scores do not appear to improve over time [24]. This study is the first study in this area which tackles problem of disability in children and impacts on children wellbeing and quality of life. Also, the study findings highlighted the need for training courses of behavioural and emotional problems in children and ways of dealing with such problems including behavioural management and using new coping strategies to overcome the adversities of disabilities and other stressors in daily life.

\section{References}

[1] World Health Organization (2007) Disability. WHO, Geneva. http://www.who.int/topics/disabilities/en/

[2] El Deeb, B. (2005) National Report on Disability Statistics in Egypt, 21-23 March 2005. www.escwa.un.org

[3] Nour, O. (2005) Child Disability in Some Countries of the MENA Region: Magnitude, Characteristics, Problems and Attempts to Alleviate Consequences of Impairments. Paper Presented at the 25th International Union for the Scientific Study of Population (IUSSP) Conference, Tours, July 2005.

[4] World Health Organization and World Bank (2011) World Report on Disability. WHO, Geneva. http://apps.who.int/iris/bitstream/10665/70670/1/WHO_NMH_VIP_11.01_eng.pdf

[5] National Society for Rehabilitation and Palestinian Medical Relief Society (2009) Recorded Database of Identified People with Disability, Based on WHO’s Criteria, 3rd Report, Issued in February 2010.

[6] Goodman, R. and Graham, P. (1996) Psychiatric Problems in Children with Hemiplegia: Cross Sectional Epidemiological Survey. British Medical Journal, 312, 1065-1068. http://dx.doi.org/10.1136/bmj.312.7038.1065

[7] Goodman, R. (1998) The Longitudinal Stability of Psychiatric Problems in Children with Hemiplegia. Journal of Child Psychology and Psychiatry, 39, 347-354. http://dx.doi.org/10.1017/S0021963097002059

[8] Einfeld, S.L. and Tonge, B.G. (1996) Population Prevalence of Psychopathology in Children and Adolescents with Intellectual Disability. II. Epidemiological Findings. Journal of Intellectual Disability Research, 40, 99-109. http://dx.doi.org/10.1111/j.1365-2788.1996.tb00611.x

[9] Barlow, J., Parsons, J. and Stewart-Brown, S. (2004) Preventing Emotional and Behavioural Problems: The Effectiveness of Parenting Programs with Children Less than 3 Years of Age. Child Care, Health, and Development, 31, 33-42. http://dx.doi.org/10.1111/j.1365-2214.2005.00447.x

[10] Parkes, J., White-Koning, M., Dickinson, H.O., Thyen, U., Arnaud, C., Beckung, E., Fauconnier, J., Marcelli, M., McManus, V., Michelsen, S.I., Parkinson, K. and Colver, A. (2008) Psychological Problems in Children with Cerebral Palsy: A Cross-Sectional European Study. Journal of Child Psychology and Psychiatry, 49, 405-413. http://dx.doi.org/10.1111/j.1469-7610.2007.01845.x

[11] Brossard-Racine, M., Waknin, J., Shikako-Thomas, K., Shevell, M., Poulin, C., Lach, L., Law, M., Schmitz, N. and Majnemer, A., QUALA Group (2013) Behavioral Difficulties in Adolescents with Cerebral Palsy. Journal of Child Neurology, 28, 27-33. http://dx.doi.org/10.1177/0883073812461942 
[12] Hughes, C. and Hwang, B. (1996) Attempts to Conceptualize and Measure Quality of Life. In: Schalock, R.L., Ed., Quality of Life: Volume 1. Conceptualization and Measurement, American Association on Mental Retardation, Washington DC, 51-61.

[13] World Health Organization (1995) Quality of Life Assessment (WHOQOL): Position Paper from the World Health Organization. Social Science Medicine, 41, 1403-1409. http://dx.doi.org/10.1016/0277-9536(95)00112-K

[14] Brown, I. and Brown, R. (2003) Quality of Life and Disability: An Approach for Community Practitioners. Jessica Kingsley, London.

[15] Schalock, R.L., Brown, I., Brown, R.I., Cummins, R.A., Felce, D., Matikka, L., et al. (2002) Conceptualization, Measurement, and Application of Quality of Life for Persons with Intellectual Disabilities: Report of an International Panel of Experts. Mental Retardation, 40, 457-470. http://dx.doi.org/10.1352/0047-6765(2002)040<0457:CMAAOQ>2.0.CO;2

[16] Eiser, C. and Morse, R. (2001) The Measurement of Quality of Life in Children: Past and Future Perspectives. Journal of Developmental Behaviour of Pediatric, 22, 248-256. http://dx.doi.org/10.1097/00004703-200108000-00007

[17] Riley, A.W. (2004) Evidence That School-Age Children Can Self-Report on Their Health. Ambulatory Pediatrics, 4, 371-376. http://dx.doi.org/10.1367/A03-178R.1

[18] Felder-Puig, R., Frey, E., Proksch, K., Varni, J.W., Gadner, H. and Topf, R. (2004) Validation of the German Version of the Pediatric Quality of Life Inventory (PedsQL) in Childhood Cancer Patients off Treatment and Children with Epilepsy. Quality of Life Research, 13, 223-234. http://dx.doi.org/10.1023/B:QURE.0000015305.44181.e3

[19] Fuemmeler, B.F., Elkin, T.D. and Mullins, L.L. (2002) Survivors of Childhood Brain Tumors: Behavioral, Emotional, and Social Adjustment. Clinical Psychology Review, 22, 547-585. http://dx.doi.org/10.1016/S0272-7358(01)00120-9

[20] Goldwein, J.W., Radcliffe, J., Johnson, J., Moshang, T., Packer, R.J., Sutton, L.N., Rorke, L.B. and D’Angio, G.J. (1996) Updated Results of a Pilot Study of Low Dose Craniospinal Irradiation Plus Chemotherapy for Children under Five with Cerebellar Primitive Neuroectodermal Tumors (Medulloblastoma). International Journal of Radiation Oncology Biology Physics, 34, 899-904. http://dx.doi.org/10.1016/0360-3016(95)02080-2

[21] Varni, J.W., Seid, M. and Kurtin, P.S. (2001) Quality of Life Inventory Version 4.0 Generic Core Scales in Healthy and Patient Populations. Medical Care, 39, 800-812. http://dx.doi.org/10.1097/00005650-200108000-00006

[22] Tao, M.L. and Parsons, S.K. (2005) Quality-of-Life Assessment in Pediatric Brain Tumor Patients and Survivors: Lessons Learned and Challenges to Face. Journal of Clinical Oncology, 23, 5424-5426. http://dx.doi.org/10.1200/JCO.2005.05.906

[23] Eiser, C. and Jenney, M. (2007) Measuring Quality of Life. Archive of Diseases of Children, 92, 348-350. http://dx.doi.org/10.1136/adc.2005.086405

[24] Varni, J.W., Burwinkle, T.M., Rapoff, M.A., Kamps, J.L. and Olson, N. (2004) The PedsQLтм in Pediatric Asthma: Reliability and Validity of the Pediatric Quality of Life Inventory ${ }^{\mathrm{TM}}$ Generic Core Scales and Asthma Module. Journal of Behavioral Medicine, 27, 297-318. http://dx.doi.org/10.1023/B:JOBM.0000028500.53608.2c

[25] Vargus-Adams, J. (2005) Health-Related Quality of Life in Childhood Cerebral Palsy. Archives of Physical Medicine and Rehabilitation, 86, 940-950. http://dx.doi.org/10.1016/j.apmr.2004.10.036

[26] Schenker, R., Coster, W. and Parush, S. (2005) Participation and Activity Performance of Students with Cerebral Palsy within the School Environment. Disability Rehabilitation, 27, 539-552. http://dx.doi.org/10.1080/09638280400018437

[27] Rosenbaum, P.L., Livingston, M.H., Palisano, R.J., Galuppi, B.E. and Russell, D.J. (2007) Quality of Life and HealthRelated Quality of Life of Adolescents with Cerebral Palsy. Developmental Medicine of Child Neurology, 49, 516-521. http://dx.doi.org/10.1111/j.1469-8749.2007.00516.x

[28] Dickinson, H.O., Parkinson, K.N., Ravens-Sieberer, U., Schirripa, G., Thyen, U., Arnaud, C., et al. (2007) Self-Reported Quality of Life of 8 - 12 Year Old Children with Cerebral Palsy: A Cross Sectional European Study. The Lancet, 369, 2171-2178. http://dx.doi.org/10.1016/S0140-6736(07)61013-7

[29] Boyle, M.H., Offord, D.R., Racine, Y.A., Szatmari, P. and Sanford, M. (1993) Evaluation of the Revised Ontario Child Health Study scales. Journal of Child Psychology and Psychiatry and Allied Disciplines, 34, 189-213. http://dx.doi.org/10.1111/j.1469-7610.1993.tb00979.x

[30] Achenbach, T.M. (1991) Manual for the Child Behaviour Checklist/4-18 and 1991 Profile. University of Vermont Department of Psychiatry, Burlington, VT.

[31] Massad, S., Nieto, G.F., Palta, J.M., Smith, M., Clark, R. and Thabet, A.A. (2011) Health-Related Quality of Life of Palestinian Preschoolers in the Gaza Strip: A Cross-Sectional Study. BMC Public Health, 11, 253-260. http://dx.doi.org/10.1186/1471-2458-11-253

[32] Gomaa, A. (2007) Genetic Eye Diseases and Genetic Counseling Services in Egypt. Community Eye Health, $20,11$.

[33] Mitra, S., Posarac, A. and Vick, B. (2013) Disability and Poverty in Developing Countries: A Multidimensional Study. 
World Development, 41, 1-18. http://dx.doi.org/10.1016/j.worlddev.2012.05.024

[34] Sawyer, M.G., Arney, F.M., Baghurst, P.A., Clark, J.J., Graetz, B.W., Kosky, R.J., Nurcombe, B., Patton, G.C., Prior, M.R., Raphael, B., Rey, J.M., Whaites, L.C. and Zubrick, S.R. (2001) The Mental Health of Young People in Australia: Key Findings from the Child and Adolescent Component of the National Survey of Mental Health and Well-Being. Australian and New Zealand Journal of Psychiatry, 35, 806-814. http://dx.doi.org/10.1046/j.1440-1614.2001.00964.x

[35] Emerson, E. and Hatton, C. (2007) The Mental Health of Children and Adolescents with Intellectual Disabilities in Britain. British Journal of Psychiatry, 191, 493-499. http://dx.doi.org/10.1192/bjp.bp.107.038729

[36] Davis, E., Shelly, A., Waters, E., Mackinnon, A., Reddihough, D., Boyd, R. and Graham, H.K. (2008) Quality of Life of Adolescents with Cerebral Palsy: Perspectives of Adolescents and Parents. Developmental Medicine and Child Neurology, 12, 193-199. 